\title{
Corticospinal Control during Reach, Grasp, and Precision Lift in Man
}

\author{
R. N. Lemon, ${ }^{1}$ R. S. Johansson, ${ }^{2}$ and G. Westling ${ }^{2}$ \\ 'Sobell Department of Neurophysiology, Institute of Neurology, London, United Kingdom and 'Department of \\ Physiology, University of Umeå, S-901 89 Umeå, Sweden
}

\begin{abstract}
Transcranial magnetic brain stimulation (TMS) was used to assess the influence of the corticospinal system on motor output in seven human subjects during a task in which they had to reach out, grasp, and lift an object. Stimuli, directed at the hand area of the motor cortex, were delivered at eight defined points during the task: during reach, at grip closure, during object manipulation, during the parallel isometric increase in grip and load forces, during the lifting movement, and while the object was held in air.

The amplitudes of short-latency EMG responses evoked by TMS in six arm and hand muscles showed a striking modulation across the different phases of the task. This modulation may well reflect phasic changes in corticospinal excitability because: (1) it did not simply reflect phasic changes in muscular activity associated with task performance, (2) it could vary inversely with the amplitude of the background EMG, and (3) it was only obtained with weak TMS intensities, below threshold for evoking responses in hand muscles of the relaxed subject.
\end{abstract}

Our results suggest that the cortical representations of extrinsic hand muscles, which act to orientate the hand and finger tips, were subjected to a strong excitatory drive throughout the reach. This drive was also observed for brachioradialis and anterior deltoid, which contribute to transport of the hand. In contrast, the intrinsic hand muscles appear to receive their strongest cortical input as the digits closed around the object, and just after the subject first touched the object at the onset of manipulation.

The isometric parallel increase in load and grip forces necessary to lift the object, which is normally triggered by tactile contact, was delayed by TMS delivered late during the reach. TMS at this time may disrupt processing necessary to control this critical phase of the task.

Key words: precision grip, sensorimotor control, transcranial magnetic stimulation, corticospinal system, hand, human]

When we reach out to grasp and lift a small object, the first goal is to adequately position the tips of the digits onto its surfaces such that a stable grasp can be established. The transport and

\footnotetext{
Received Nov. 15, 1994; revised May 1, 1995; accepted May 4, 1995.

This work was supported by the Swedish Medical Research Council (project Office of Naval Research, Arlington, VA (Grant N00014-92-J-1919) and Charles Slater Fund, Cambridge, which are gratefully acknowledged. We thank particularly $A$. Bäckström for technical assistance.

Correspondence should be addressed to Professor Roger Lemon, Sobell Department of Neurophysiology, Institute of Neurology, Queen Square, London WC1N 3BG, UK.

Copyright @ 1995 Society for Neuroscience 0270-6474/95/156145-12\$05.00/0
}

shaping of the hand reflect a precise coordination to achicve the necessary spatio-temporal features for arresting the reach, and for an appropriate closure of the fingers around the ohject (Jeannerod, 1984, 1986; Iberall et al., 1986). Importantly, marked reductions in the intertrial variability of finger tip position occur during the deceleration of the reach movement prior to contact, suggesting that the demand for precise control gradually increases while approaching contact (e.g., Paulignan et al., 1991).

Once the digits contact the object the goal is to generate the necessary finger tip forces to lift it. This action evolves in a series of phases each delineated by discrete mechanical events and associated responses in tactile afferents from the digits (Johansson and Westling, 1984, 1987, 1988; Westling and Johansson, 1987). The initial contact marks the beginning of the first phase, the preload phase. After contact has been established by a small increase in the grip force (normal to the grip surface), the subsequent load phase is characterized by the grip force increasing in parallel with the load force (i.e., the lift force tangential to the contact area). When the load force has overcome the weight of the object it starts to move (transitional phase) into the desired vertical position (static phase). One specific role of sensory organs in the hand is to link the various phases of the lifting task by informing the CNS that particular mechanical events have occurred, for example, that the digits have made a stable contact with the object, or that the object has started to move. The magnitudes of the finger tip forces are parameterized by implicit memory information of both the friction at the digitobject interface and the object's weight, acquired during previous manipulation of the object (for a review, see Johansson and Cole, 1994). Tactile input provides information about the actual friction after initial contact has been made, and information about the actual weight is conveyed at the onset of the object's vertical movement.

There is evidence that the control of grasping and manipulation relies on distributed processes in the CNS, engaging most areas known to be involved in sensorimotor control (e.g., Smith et al., 1975; Muir and Lemon, 1983; Jeannerod, 1986; Pause et al., 1989; Espinoza and Smith, 1990; Colebatch et al., 1991; Wannier et al., 1991; Goodale and Milner, 1992; Lemon, 1993; Maier et al., 1993; Picard and Smith, 1993). As far as the execution of the task is concerned, the primary motor cortex is an obvious candidate for investigation. Through its descending influences upon the spinal cord, the motor cortex can modulate activity in all of the motoneurone pools involved in reach and grasp (Porter and Lemon, 1993, pp 186-193), and the corticomotoneuronal pathway appears to be particularly important for the execution of skilled hand tasks (Kuypers, 1981; Lemon, 
1993). Noninvasive transcranial magnetic brain stimulation (TMS) of the motor cortex in man evokes short-latency responses in most upper limb muscles (Rothwell et al., 1991), and the form and latency of the earliest component of these responses suggest that they are mediated by the direct, corticomotoneuronal pathway (Day et al., 1989a; Edgley et al., 1990; Palmer and Ashby, 1992a). Previous studies have shown that the size of muscular responses evoked by TMS may be to some extent be dependent on the level of cortical activity (Datta et al., 1989; Day et al., 1991; Palmer and Ashby, 1992b; Flament et al., 1993; Baker et al., 1994).

In this study we have used TMS directed towards the hand area of the primary motor cortex, to assess the influence of the corticospinal system on the motor output during the various phases of a task requiring the human subject to reach for an object, grasp and lift it. Specifically, we hypothesized that the influence of the motor cortex over the hand muscles should be particularly high during the final positioning of the digits prior to touch and during the early lifting phases, that is, during phases which should be particularly demanding in terms of sensorimotor control.

Preliminary results of this investigation have been published (Johansson et al., 1993).

\section{Materials and Methods}

Experiments were performed on seven subjects (four male, three female), ranging in age from 21 to 43 years. All gave their informed consent and the experimental protocol was approved by the local ethical committee.

Experimental task. Subjects sat in front of a small table with the right hand resting on the right knee, with the tips of the index finger and thumb in contact, ca. $25 \mathrm{~cm}$ from a test object. On instruction, they reached forward to grip the object between the tips of the thumb and index finger, lift it from the table up to a height of ca. $30 \mathrm{~mm}$, hold it in air for about $2.5 \mathrm{sec}$ and then, on instruction, replace it on the table. Subjects were instructed to execute the task at their preferred speed, and to keep their three ulnar fingers extended while gripping and lifting the object. 'The object was $43 \mathrm{~mm}$ long, $28 \mathrm{~mm}$ broad and $150 \mathrm{~mm}$ high; it weighed $650 \mathrm{gm}$. The two parallel grip surfaces $(60 \mathrm{~mm} \times 43$ $\mathrm{mm}$, spaced $28 \mathrm{~mm}$ apart) were located at the top of the long sides of the object. The trajectory of the subject's reach was approximately horizontal, and the grip aperture on contact was thus the same as the breadth of the object $(28 \mathrm{~mm})$. The contact surfaces of the object consisted of fine grain sandpaper (\#320). The object was instrumented so that the grip and load forces (normal and tangential to the grip surfaces respectively) could be measured at the two separate grip surfaces (fre quency response, $\mathrm{DC}-120 \mathrm{~Hz}$ ). Unless otherwise indicated, the grip force was represented as its mean value at the two grip surfaces, and the load force was the sum of the tangential forces measured at the two surfaces. The vertical position of the object was also monitored (DC $60 \mathrm{~Hz})$.

The trajectories of the subject's reach and grip were recorded by a custom-built reflex marker camera system which scanned an area of $500 \times 500 \mathrm{~mm}$ and which had a spatial resolution of $0.25 \mathrm{~mm}$. The camera (attached to the ceiling) tracked the position in the horizontal plane of four markers placed on the wrist, on the tips of the index finger and thumb, and on the upper surface of the object (Fig. 1).

$E M G$ recording. Surface EMGs were recorded from two intrinsic hand muscles, first dorsal interosseous (1DI) and abductor pollicis brevis ( $\mathrm{AbPB}$ ); from two extrinsic hand muscles, extensor digitorum communis (EDC) and flexor digitorum superficialis (FDS) and from the arm muscles, brachioradialis (Brr) and anterior deltoid (Delt). EMG was recorded using shielded preamplifiers (bandwidth $6 \mathrm{~Hz}$ to $2.5 \mathrm{kHz}$ ) mounted on the skin directly above the surface electrodes; these electrodes were $2 \mathrm{~mm}$ in diameter and $12 \mathrm{~mm}$ apart. They were coated with electrode jelly and then firmly attached to the skin using double-sided adhesive tape. EMG records were carefully monitored for stimulus artifacts, noise, and cross-talk.

Transcranial magnetic stimulation. Magnetic stimuli were delivered from a Digitimer D190 stimulator using an angled $\left(100^{\circ}\right)$ figure-of-eight coil (diameter of each coil: $140 \mathrm{~mm}$ ) positioned with the junction region over the left hemisphere and located at the optimal position for evoking a short-latency response in the IDI of the relaxed subject. The weight of the coil and its cable was carefully counterbalanced with rubber bands suspended from an overhead gantry and the coil secured to the subject's head with velcro straps. Coil landmarks were referenced to marks on the subject's scalp. The threshold ( $T$ ) for responses in the relaxed IDI muscle were repeatedly checked between each series of trials. This value, which ranged from 38 to $50 \%$ of maximum stimulator output, never changed by more than $5 \%$ of stimulator output during the course of a single experiment.

Timing of magnetic stimuli. Stimuli were delivered at eight different times relative to task performance, as shown in Figures 1 and 2 ; only one stimulus was given per trial. Stimuli delivered during the reach (stimulation point $1-3$ ) were triggered on line relative to spatial coordinates as the hand and fingers approached the object (Fig. 1). The difference along the $\mathrm{x}$-axis between the index finger marker and the object was continuously computed. The mid-reach phase (1) and latereach phase (2) stimuli were triggered when this difference was 150 $\mathrm{mm}$ and $30 \mathrm{~mm}$ from the object, respectively. The pretouch (3) stimulus was delivered when the thumb and index finger began to close upon the object (see Figs. 1 and 2). On average it was delivered when the finger tip was $6.0 \mathrm{~mm}( \pm 3.7 \mathrm{~mm} ; \mathrm{SD})$ from its position along the $\mathrm{x}$-axis at the moment the object was first touched. Due to the interindividual variability in grasping the object and the exact placement of the nailmarker, the $\mathrm{x}$-coordinate actually used for triggering was adjusted for the individual subject from data gathered during a series of test trials run before the actual data acquisition (see below). At the pretouch TMS, the distance between the finger tip and the grasp surface of the object was $9.4 \mathrm{~mm}( \pm 1.6 \mathrm{~mm})$.

Stimuli delivered after the object was touched were triggered relative to the grip or load forces generated by the subject at five points (Fig. 2): The "touch" (4) stimulus was delivered soon after contact $(0.12 \pm$ $0.05 \mathrm{sec}$ ) and was triggered by the grip force exceeding $0.8 \mathrm{~N}$; the "load" (5) stimulus at the middle of the loading phase (load force $=$ $2.7 \mathrm{~N}$ ); the "transition" (6) stimulus close to the transition between the load and movement phase (load force $=5.8 \mathrm{~N}$ ); the "lift" (7) stimulus during the lift movement, $0.2 \mathrm{sec}$ after lift off (object was $8.7 \pm 6 \mathrm{~mm}$ above the table); the "static" (8) stimulus during the static or hold phase after the object had been in the air for $2 \mathrm{sec}$.

Experimental procedure. After a short test period, during which 20 30 magnetic stimuli were delivered and the recording system was evaluated (e.g., gain setting of EMG channels, measurements of $x$-coordinate of the index finger marker at moment the object was first touched, etc.), the stimulus strength was set to a fixed multiple of $T$, that is, 0.7 $T, 0.8 T$, or $0.9 T$. A series of 81 trials was then sampled, each of which lasted about $5 \mathrm{sec}$, and the intertrial interval was $2 \mathrm{sec}$. The presentation of stimuli was randomized throughout the trials, and control trials, in which no stimuli were delivered, were intermixed with stimulated trials. Nine trials were sampled for each condition $(8 \times 9$ stimulated trials plus 9 controls $=81)$. The position of the coil and threshold $(T)$ were then checked, and a new series of 81 trials commenced using a different stimulus intensity. Each subject had one series for each of these three stimulation intensities.

Data acquisition and analysis. All signals were stored and analyzed using the SC/ZOOM microcomputer-based data acquisition and analysis system (Department of Physiology, University of Umeå). The grip and load forces at the two grip surfaces of the test object (DC $-120 \mathrm{~Hz}$ ) were digitized (12 bits) at $400 \mathrm{~Hz}$, and the its vertical position at 100 $\mathrm{Hz}$. The kinematic data (see Fig. l) were also sampled at $100 \mathrm{~Hz}$. EMG from each channel was root-mean-square (r.m.s.) processed with a rise time constant of $1.0 \mathrm{msec}$ and a decay time constant of $3.0 \mathrm{msec}$ and sampled at $400 \mathrm{~Hz}$. Event markers related to the timing of TMS were also sampled $( \pm 0.1 \mathrm{msec}$ resolution).

All measurements were made from single trials. For each muscle the background EMG amplitude was measured as the r.m.s. voltage $10 \mathrm{msec}$ before or after the TMS pulse. The computer searched each channel of r.m.s. processed EMG for a peak voltage occurring between 10 and 40 msec after the magnetic stimulus, that is, the short-latency component of the EMG response evoked by the TMS (Rothwell et al., 1991). These peak voltages were confirmed interactively. Since the distributions of both the background and peak amplitude EMG measurements typically were positively skewed they were transformed to a logarithmic scale, that is, the distributions were log-normal rather than normal.

To confirm that our measurements were made on the short-latency 

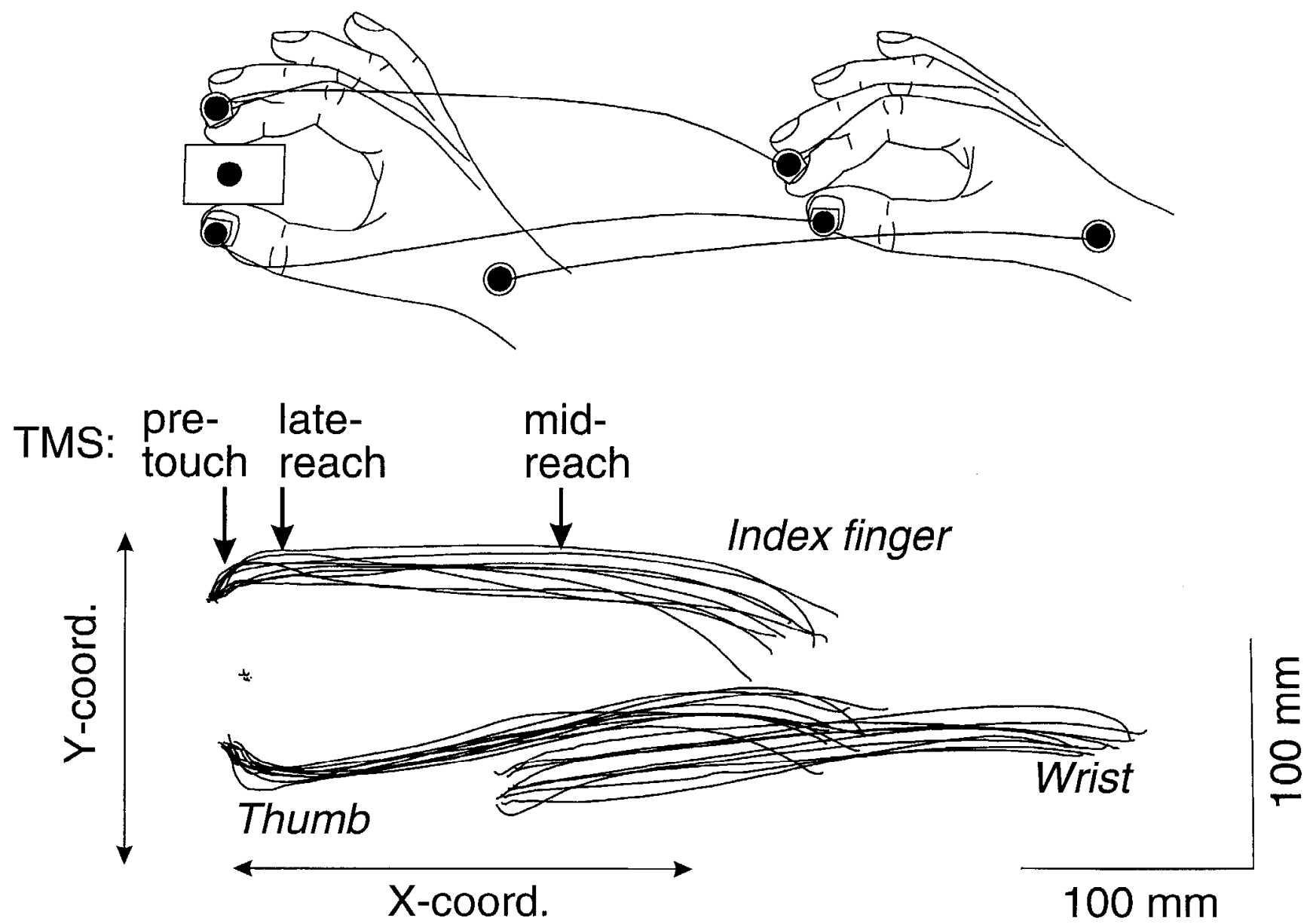

Figure I. Kinematics of the reach during the reach-lift task. Data were recorded in the horizontal plane with a CCD camera using reflex markers attached to (1) top of test object, (2) nail of index finger, (3) nail of thumb, and (4) the wrist. At the beginning of each trial the hand rested on the knee with contact between the tips of index and thumb. The reaching movement took place in the horizontal plane. Transcranial magnetic brain stimulation (TMS) delivered during mid-reach, late-reach, or pre-touch phases was triggered on line from spatial coordinates of the index finger marker as specified in Materials and Methods. Curves indicate trajectories superimposed from consecutive trials carried out by a single subject with no TMS.

component of the response to TMS, we measured the onset and peak latencies of all EMG responses in all six muscles. Measurements were taken from peaks greater than 2.5 times the background EMG level, and data were gathered at all intensities of TMS used. The difference between peak and background voltage was determined and the latency taken as the first point after stimulus delivery when the voltage had increased by $10 \%$ of this difference. The mean ( \pm SD) onset latencies of the responses, together with the number of trials measured (in brackets), were as follows: anterior deltoid (Delt), $13.6 \pm 1.7 \mathrm{msec}(n=$ 509); brachioradialis (Brr), $17.5 \pm 2.6 \mathrm{msec}$ (1053); extensor digitorum communis (EDC), $18.1 \pm 2.3 \mathrm{msec}(1021)$; flexor digitorum communis (FDS), $19.5 \pm 1.9 \mathrm{msec}(1017)$; abductor pollicis brevis (AbPB), 22.1 $\pm 2.6 \mathrm{msec}(71 \mathrm{l})$; and first dorsal interosseous (1DI), $22.7 \pm 2.6 \mathrm{msec}$ (770). The mean peak latencies were: Delt, $21.6 \pm 4.2 \mathrm{msec}$; Brr, 26.2 $\pm 4.6 \mathrm{msec}$; EDC, $24.9 \pm 3.7 \mathrm{msec}$ FDS, $26.5 \pm 3.3 \mathrm{msec}$; AbPB, $28.2 \pm 3.7 \mathrm{msec}$; and 1DI, $28.8 \pm 3.9 \mathrm{msec}$, respectively (data from all seven subjects pooled). These latencies are similar to those described in earlier studies (see Rothwell et al., 1991).

For each trial and muscle, the ratio between the peak amplitude of the TMS evoked EMG response and the background EMG activity was calculated by subtracting the logarithm of the background voltage from that of the peak voltage. The mean ratio was then estimated (on the logarithmic scale) from the nine trials for that particular stimulus condition (intensity, point of stimulation during the trial and subject). For each muscle and subject, we then selected for further analysis the results obtained with only one of the intensities tested, that is, those obtained from the series of trials which produced the greatest modulation in that muscle's responses across the different phases of the task. In most cases this was the $0.8 T$ intensity (mean $0.81 T \pm 0.06$ (SD) across all muscles and subjects).

The points in time when each of the two digits initially contacted the object were determined from the first time derivatives of the scparatc grip force signals ( \pm 5 point numerical differentiation).

Statistics. For each of the dependent variables (peak amplitude of the TMS evoked EMG response, background EMG amplitude, and the ratio between these two), differences across the various stimulation points of the trial were assessed using multiple linear regression. Data from the static point of the task (8) were compared with corresponding data from each of the other stimulation points (1-7). Each stimulation point was coded as a separate independent variable with the value 1 if the point had been stimulated during the current trial, and 0 if had not (for details regarding this statistical method, see Neter et al., 1989, pp 349-370). A probability of 0.01 or less was required for a significant test result. In addition, nonparametric statistics (Siegel and Castellan, 1988) were used as specified in the text. Unless otherwise stated all values reported refer to data pooled from all subjects, and means \pm SDs are given in the text.

\section{Results}

General description of task performance

Figure 2 illustrates averaged data from control (unstimulated) trials $(n=9)$ performed by one subject. The time from start of reach to initial contact was $0.86 \mathrm{sec}( \pm 0.18 \mathrm{sec})$. 'The unimodal velocity profile of the index finger marker peaked at $0.49 \mathrm{sec}$ 


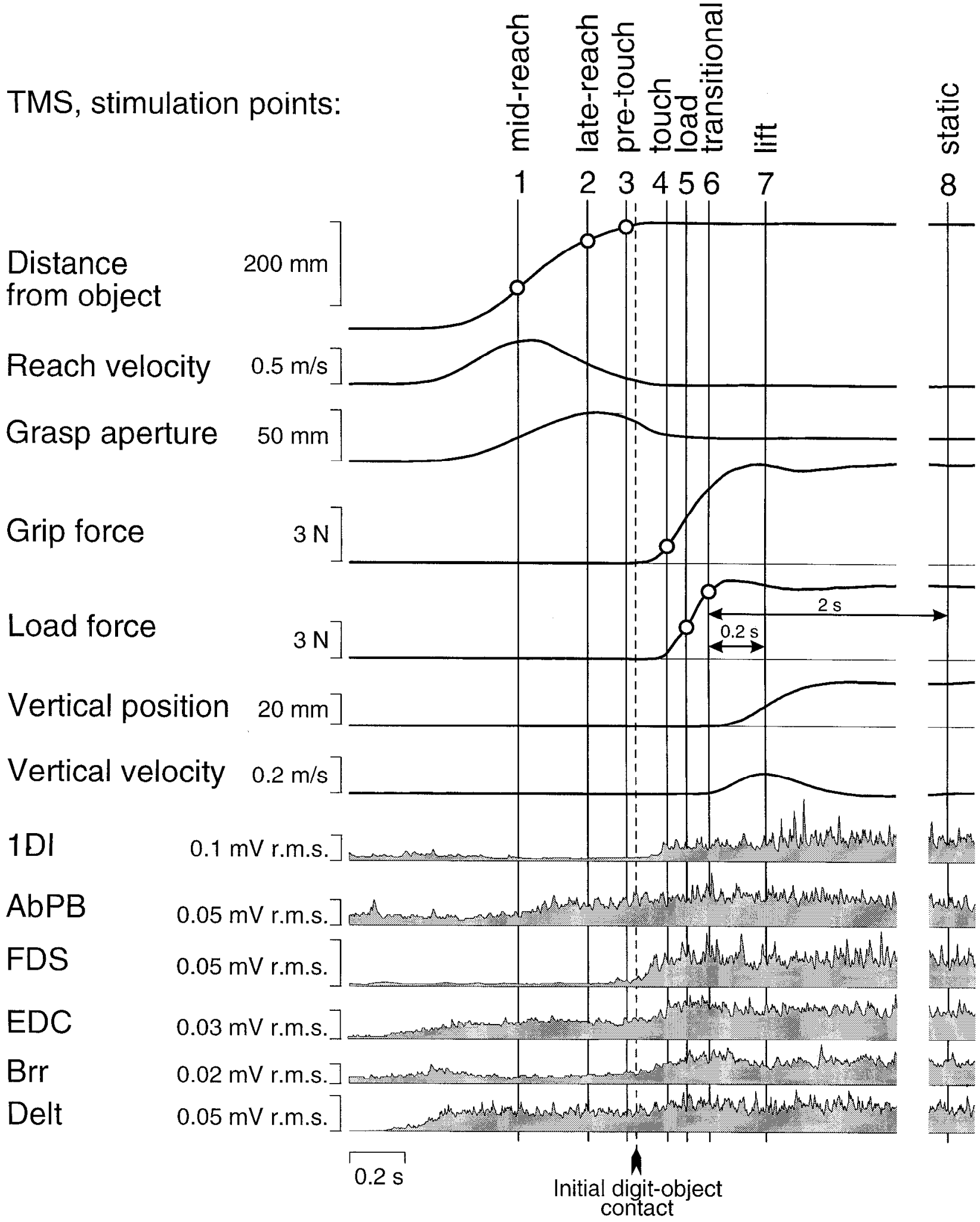

Figure 2. Ensemble averages of kinematic, force and EMG recordings across all control trials in a series of trials by a single subject $(n=9)$. The distance from the object was derived from the x-coordinates of the index finger and object markers (Fig. 1), and the grasp aperture from the $y$-coordinates of the markers on the tips of the thumb and index finger (Fig. 1). Reach and vertical velocity were estimated as the first time derivative of the distance from the object and its vertical position, respectively. R.m.s. processed EMGs from the following muscles are shown: first dorsal interosseous $(I D I)$, abductor pollicis brevis $(A b P B)$, flexor digitorum superficialis $(F D S)$, extensor digitorum communis $(E D C)$, brachioradialis $(B r r)$, and anterior deltoid (Delt). Vertical lines relate the points in time of the TMS to the control trials; the timing of the TMS points was referenced on line to kinematic recordings (points 1-3) and grip and load force recordings (points 4-8) as detailed in Materials and Methods. The channel that provided the trigger information is encircled at the relevant point. Data averaging was referenced to the 'touch' trigger. The vertical dashed line indicates the first point of contact with the object. 


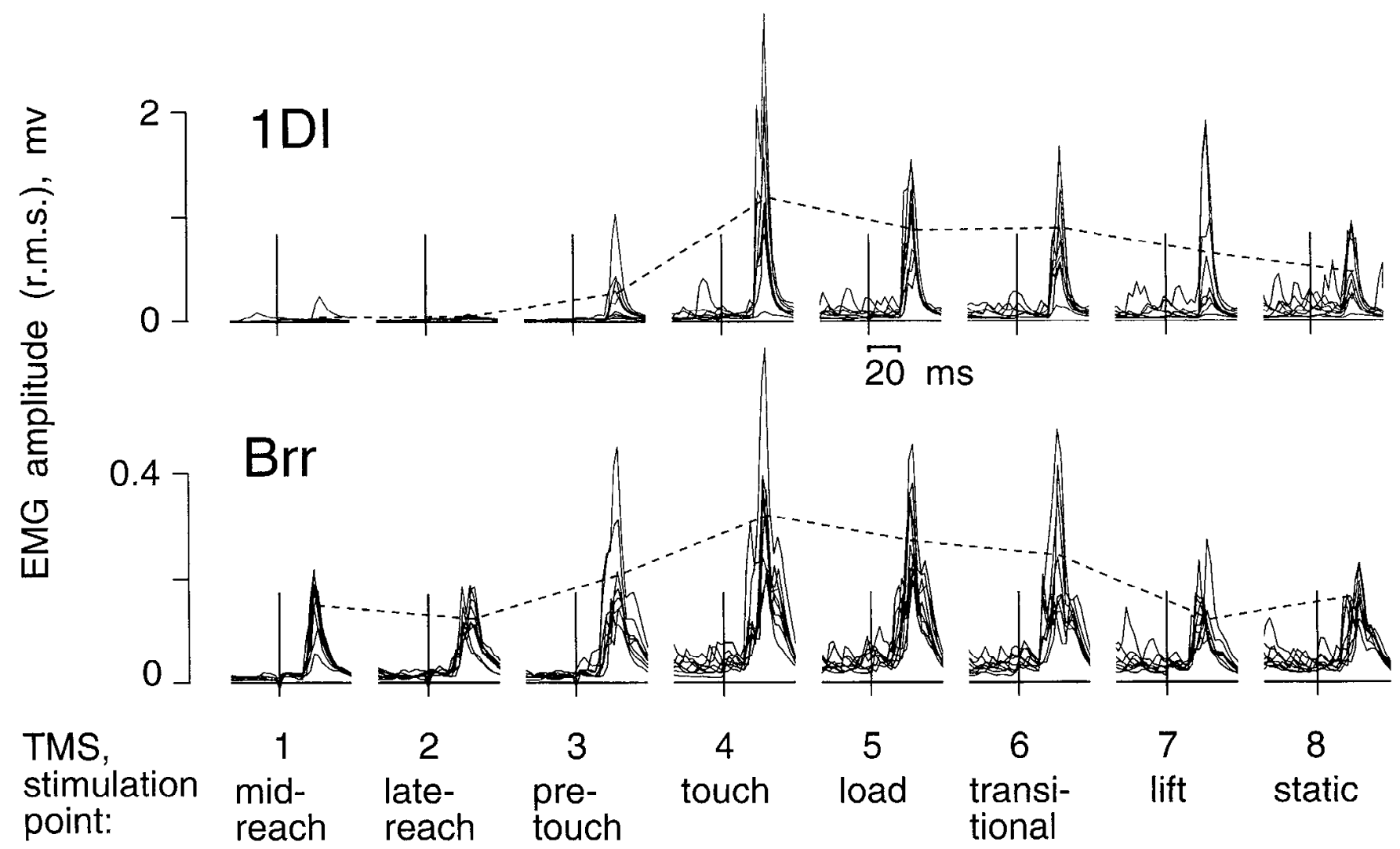

Figure 3. Examples of TMS evoked EMG responses in 1DI and Brr obtained from a single subject during the reach-lift task. Data from nine single trials superimposed for each of the eight point of stimulation during the trials (i.e., a complete data set from one series of trials is represented). The vertical lines indicate the timing of TMS delivery. The dotted line shows the mean values of the peaks of the TMS evoked responses. EMG has been r.m.s. processed and rectified. TMS strength was $0.8 T$.

$( \pm 0.14 \mathrm{sec})$ prior to contact. Grasp aperture (gauged as the distance between the index finger and thumb markers) increased during the reach to a maximum at $0.22 \mathrm{sec}( \pm 0.09 \mathrm{sec})$ prior to contact before beginning to close around the object. As described in previous reports from this laboratory (Johansson and Westling, 1984), after a preload phase (lasting ca. 0.1 sec) during which the grip was established, the grip force and the load force increased in an approximately parallel manner during the subsequent loading phase. When the load force overcame the force of gravity acting on the object, it began to move upwards 0.42 $\sec ( \pm 0.15 \mathrm{sec})$ after it was first contacted by the subject.

All six sampled hand and arm muscles showed a marked activity during object manipulation (cf. Johansson and Westling, 1988), but all of them were also active during the reach prior to contact with the object, although the first dorsal interosseous (IDI) and the flexor digitorum superficialis (FDS) showed low activity (Fig. 2). The short abductor of the thumb (AbPB) increased its activity as the grasp aperture widened during the reach, but this muscle also showed clear cocontraction with 1DI during the grip itself.

Figure 2 also shows the occurrence of the TMS points relative task performance, the "mid-reach" point (1) occurred close to the peak of the reach velocity, the "late-reach" point (2) close to the maximum grasp aperture, and the "pre-touch" point (3) during the decreasing grasp aperture prior to contact with the object. The "touch" point (4) occurred near the onset of load force increase, the "load" point (5) near the peaks of both grip and load force rate during the load phase (not illustrated in Fig.
$2)$, the "transitional" point (6) close to lift-off, and the "lift" point (7) close to peak of the vertical velocity.

\section{Modulation in amplitude of TMS evoked EMG responses during the various phases of the task: IDI and Brr}

Examples of short-latency responses to TMS recorded from 1DI and Brr in one subject are shown in Figure 3. Responses in both muscles showed a similar pattern, with an increase in response amplitude during the pre-touch stimulation (point 3), maximum response for stimuli delivered at touch (point 4 ), and a general decline through the succeeding stimulation points $t o$ a significantly smaller response during the static phase (point 8).

Since each of the sampled muscles showed clear changes in activity during the task (Fig. 2; see further below), variation in the amplitude of the responses to TMS delivered at different points may have simply reflected changes in motoneuronal excitability. To examine this possibility we normalized the peak amplitude of the I'MS evoked response to the level of background EMG activity by the computing peak:background ratio (cf. Johansson ct al., 1994).

Figure $4, A$ (1DI) and $D$ (Brr), shows the changes in the amplitude of the background EMG (lower curve) and peak amplitude of the response (upper curve) for the same subject as in Figure 3 , and the corresponding normalized responses are given in Figure $4, B$ and $E$. If the response amplitude during the different stimulation points had simply varied in proportion to the background EMG, these ratio plots would be represented as horizontal lines. But in fact there was a marked modulation in the 

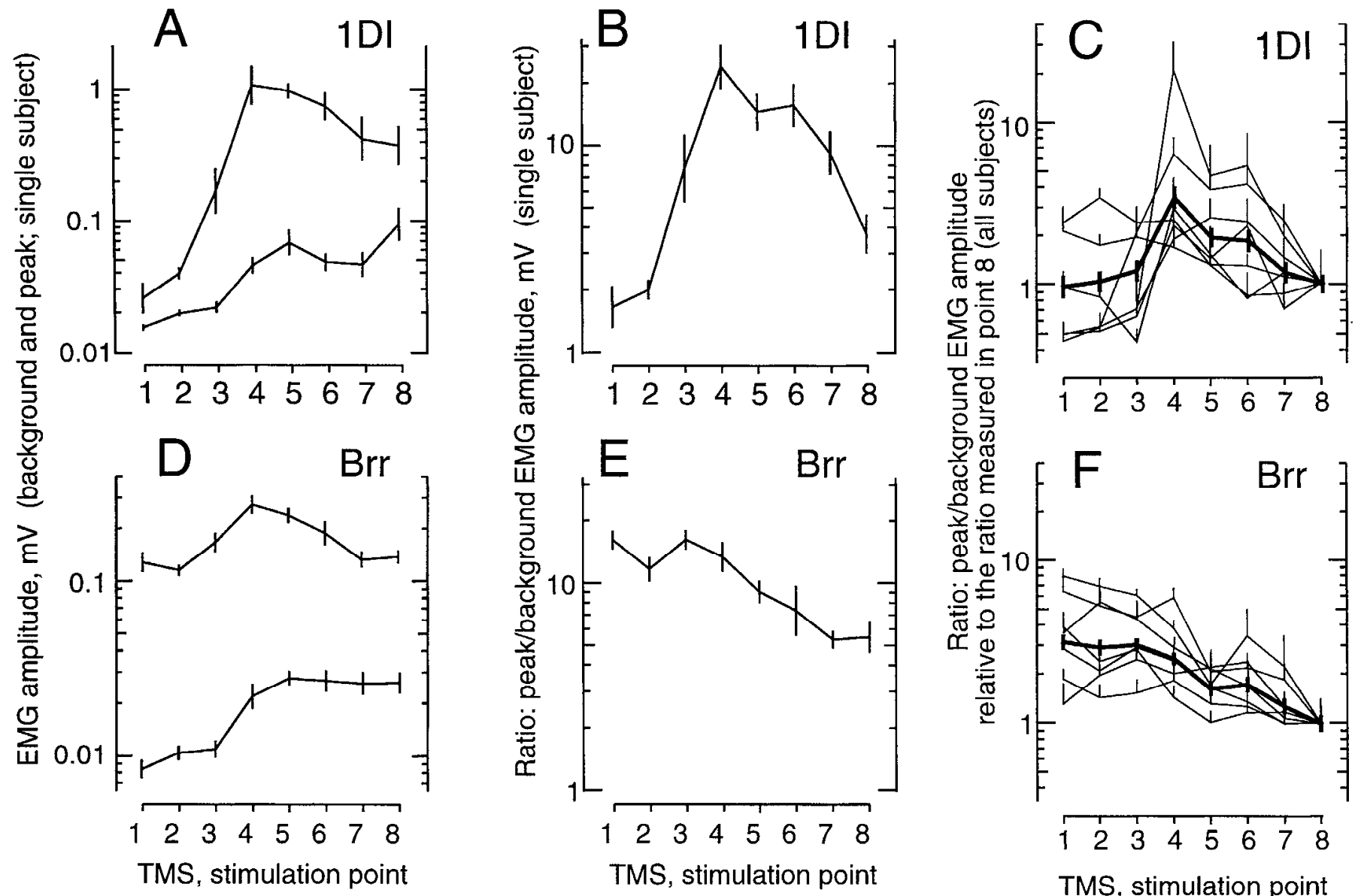

Figure 4. Variation in responses to TMS during the task. Background EMG, peak amplitudes of the EMG responses to TMS, and peak:background amplitude ratios across the eight TMS points $(I-8)$ for IDI $(A-C)$ and BII $(D-F)$. A and $D$, Amplitude of the backgroumd EMG (lower curve) and peak amplitude of the response to TMS (upper curve) for a single subject (same as in Fig. 3). $B$ and $E$, Peak:background ratio for the same data as in $A$ and $D . C$ and $F$, Corresponding peak:background ratios from all subjects superimposed (thin lines) and their means across all subjects (thick line). All curves are normalized to the ratio measured at the static TMS point $(8)$ by dividing the value of each data point by this ratio. $A-$ $F$, Measurements are joined by straight lines and the vertical bars indicate the mean \pm 1 SEM $(+1$ SEM in $C$ and $F)$. Note the logarithmic scale of the ordinates.

relative amplitude of the EMG responses to TMS across the stimulation points. For 1DI in this subject, both the largest TMS evoked response and the largest peak:background ratio occurred at touch (point 4), where the peak response amplitude was around 25 times larger than the background EMG. The ratio then declined steadily over points $5-8$, to a value of around 4 during the static phase. This fall was due to an increase in the background EMG with a concomitant decrease in the TMS evoked response. Note that despite the low and rather uniform level of activity in 1DI during the reach, a strong modulation in the responses to TMS occurred during this period (cf. points 2 and 3). Although the largest responses to TMS in Brr also occurred at touch, the relative size was similar to that obtained during the reach (points 1 and 3 ).

The peak:background ratios from all seven subjects for responses recorded in 1DI and Brr are superimposed in Figure 4, $C$ and $F$, respectivcly. To make possible a direct comparison of the data from individual subjects, the ratio obtained during the static phase (point 8) of the task was given the value 1 for each subject. The heavy line indicates the mean values for all subjects. Despite a considerable variability, essentially the same pattern of modulation was present in all subjects. For 1DI, the largest effects were produced by TMS at the touch point, with a steady decline towards to the static phase. With Brr, for most subjects the peak:background ratio was large during the reach (points 1-3) and touch (4) before falling to the lowest ratio during the static phase (8).

In one subject the 1DI showed very low background EMG during the first two stimulation points (i.e., during the mid- and late-reach) that could not be reliably measured. A similar pattern of responses was found in FDS in this subject. Since the absence of any reliably measurable background activity in the muscle could produce spurious peak-background ratios, these data were excluded from analysis, which explains why only six subjects are represented for points 1 and 2 in Figure $4 C$.

\section{Modulation in amplitude of EMG responses to TMS in different muscles}

Figure 5 shows pooled data from all subjects for the six different muscles studied. The lower set of graphs show the peak amplitude of the response to TMS (upper curve) and the background EMG level across the different stimulation points (lower curve). The upper graphs plot the ratio peak:background amplitude. The boxes superimposed upon the ratio curves indicate the percentage changes relative to the static point ratios; the ratio during the static point (8) has been taken as $100 \%$, and the horizontal 


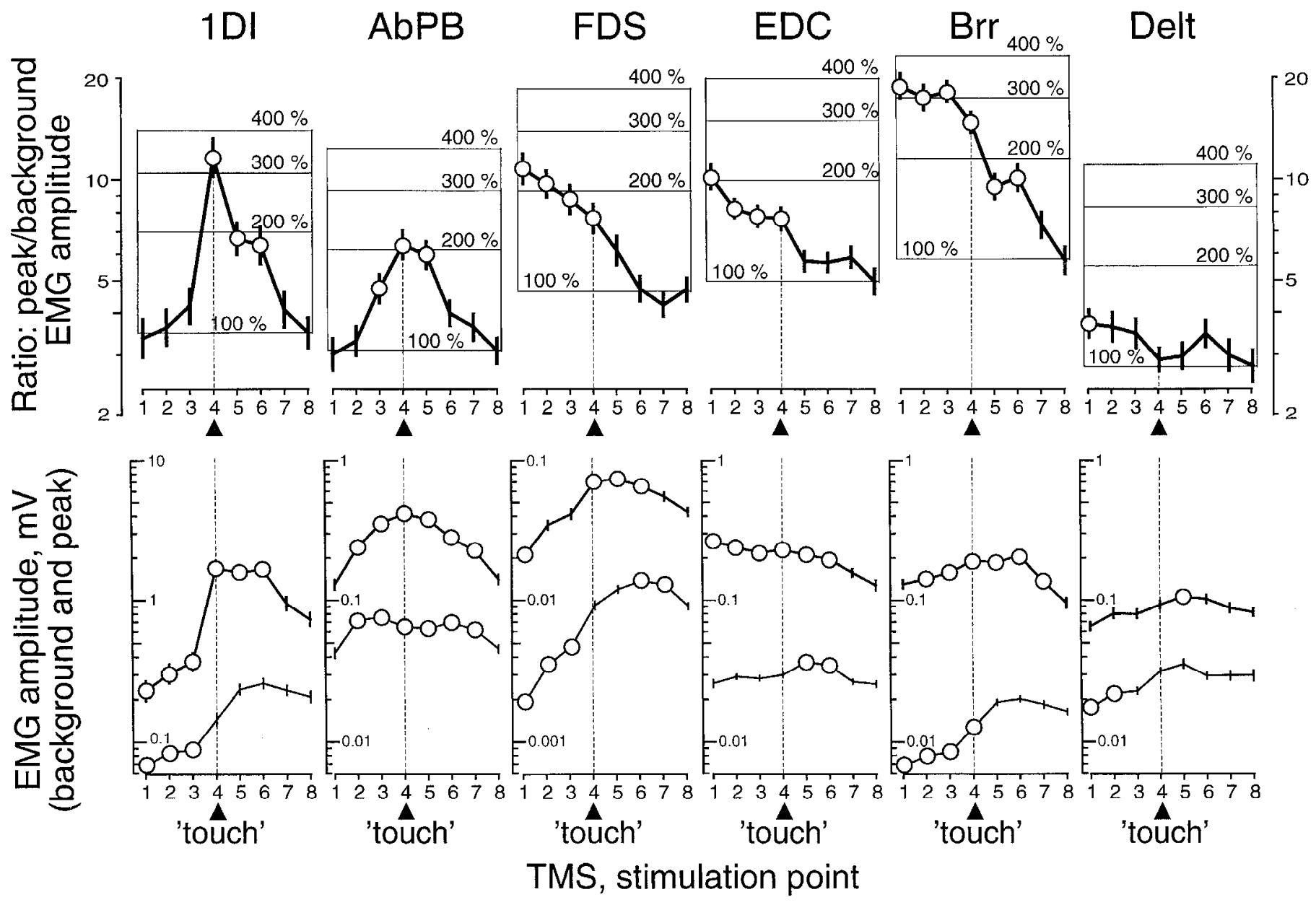

Figure 5. Pooled results from seven subjects showing variation in responses to TMS during the task. Background EMG, peak amplitude of the EMG responses to TMS (lower graphs) and the measured peak:background ratio (upper graphs) for the eight TMS points ( $1-8$ ) and all six muscles investigated. The measurements are joined by straight lines and the vertical bars indicate the mean \pm 1 SEM. Dashed vertical lines are aligned with the first stimulus point following contact with the object ('touch"). Circles indicate that the data point is significantly different from the corresponding value at the static phase (point 8$)(p<0.01$, multiple linear regression as described in Materials and Methods). Boxes superimposed on the ratio curves indicate the percentage changes in relation to the static values $(100 \%)$. Note the logarithmic ordinates. For abbreviations, see Figure 2 caption.

lines indicate when the size of the average peak:background ratio would have been 200,300 , or $400 \%$ greater than that found for the static point. Modulation was most marked for Brr and $1 \mathrm{DI}$; in the latter the peak:background ratio was around $320 \%$ of the static value at touch (point 4). AbPB, EDC and FDS all exhibited changes around $200 \%$. In contrast, there was little modulation in the anterior deltoid (Delt).

Figure 5 shows that the modulation in the influence of TMS across the task varied considerably for different muscles. Thus brachioradialis showed the highest ratios during the reach (points 1-3), despite being less active during the reach than during manipulation. Likewise, the FDS showed high ratios during the reach. The EDC muscle, which, in most subjects, showed nearly constant background EMG activity throughout the task (see Fig. 5, lower curve), still showed high peak:background ratios during the reach.

In clear contrast to the pattern seen in Brr, FDS, and EDC, both of the intrinsic hand muscles, IDI and AbPB, exhibited maximum ratios at touch (point 4), and responses evoked early in reach did not differ significantly from the static point. Despite the similarity in the ratios for 1DI and AbPB (upper curves in Fig. 5), their pattern of activity across the task was quite differ- ent. EMG activity in 1DI resembled that in Brr whereas the AbPB exhibited a rather uniform activity from late-reach (point 2) to lift (point 7). The increase in AbPB activity from midreach (point 1) to late-reach (point 2) was probably related to the opening of the grasp aperture before the hand was preshaped for the grasp (cf. Fig. 2).

\section{Lack of modulation in responses evoked by high intensity TMS}

The modulation in amplitude of the response to TMS described above was dependent on the stimulus intensity used. In all subjects, intensities of $0.7,0.8$, and $0.9 T$ were tested. In the majority of cases ( 24 out of 42 cases, 7 subjects $\times 6$ muscles) the greatest modulation in response amplitude was obtained with the $0.8 T$; responses were often weak or difficult to discriminate at $0.7 T$ and were less well modulated at $0.9 T$, where they tended to follow the background EMG activity. There was no obvious trend for the more proximal muscles (Delt and Brr) to show a better modulation at a higher intensity than for the distal muscles.

In a separate series of experiments on four subjects, we investigated responses in 1DI with stimuli that were at threshold for responses in the relaxed 1DI muscle (1.0 T), and compared 


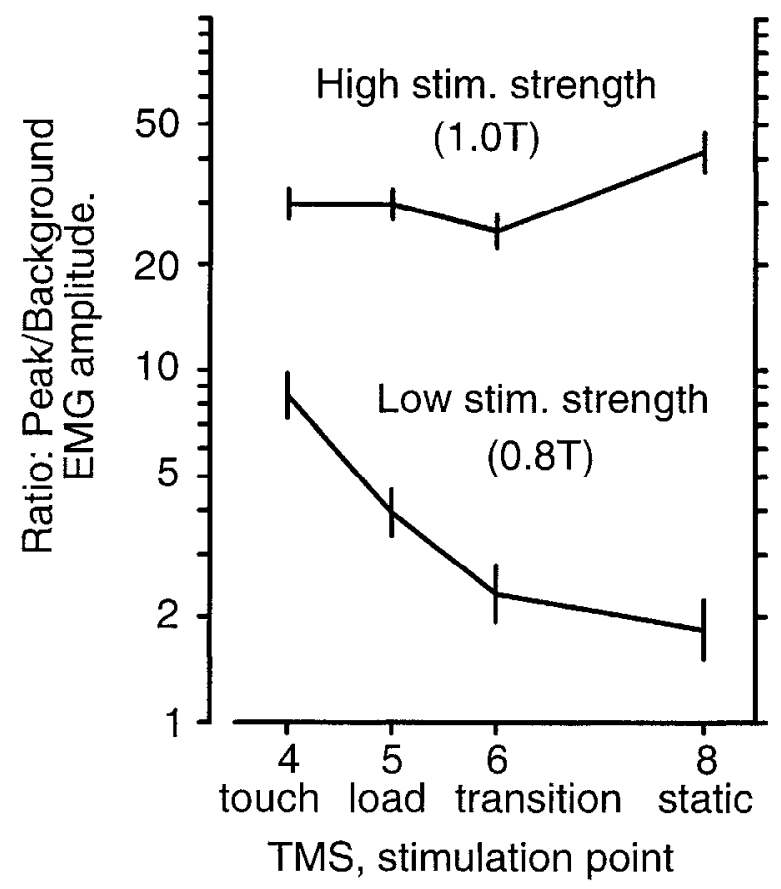

Figure 6. Lack of modulation in EMG responses evoked by high intensity TMS in 1DI. Peak:background ratios for stimulation points during manipulation of the object (points 4-8 in Fig. 2) are shown. Upper and lower curves refer to high and low stimulation strength $(1.0 \pm 0.1$ and $0.8 \pm 0.1$ times threshold of the relaxed 1DI muscle, respectively. The measurements are joined by straight lines, and the vertical bars indicate the data points (mean \pm 1 SEM). Data pooled from separate series of trials on four subjects $(4 \times 9$ trials per stimulation point). Note the logarithmic ordinate. them with those elicited in the same session using weaker intensities, similar to those used while collecting the data described above $(0.8 T)$. The results are shown in Figure 6 . In these experiments only stimuli delivered during points $4,5,6$, and 8 were investigated. At the low intensity, the same striking modulation of activity was seen, as already described (cf. Fig. 5). At the higher intensity, where all responses were much larger (about 30 times the background value), there was little or no modulation of this ratio with phase of the task. The approximately horizontal line indicates that the TMS evoked response now varied in proportion to the background EMG across the different stimulation points.

\section{Effects of magnetic stimulation on task performance}

The ability of subjects to perform the task was not impaired by the low intensities of TMS used in this study. The small twitches of the actively contracting arm and hand muscles elicited by the TMS resulted in some small departures from the kinematic pattern during the reach for the object compared to that of the control trials, and some changes in the applied forces (Fig. 7).

Furthermore, TMS delivered during later phases of manipulation often resulted in a maintained small increase in the grip force compared to that seen in control trials (see points $5-7$ in Fig. 7). A similar effect of TMS delivered to the hand area was observed in an earlier study in which the subject's task was to restrain an object held in a precision grip while it was subjected to unpredictable loads (Johansson et al., 1994).

However, there was one particularly striking effect caused by TMS which is illustrated in Figure 8 . In accord with previous observations, in control trials all subjects showed a delay of around $0.1 \mathrm{sec}$ from the moment of initial digit contact to the onset of the load phase (Johansson and Westling, 1984). However, with TMS delivered during the reach, the duration of this "preload" phase could increase substantially. The strongest ef-

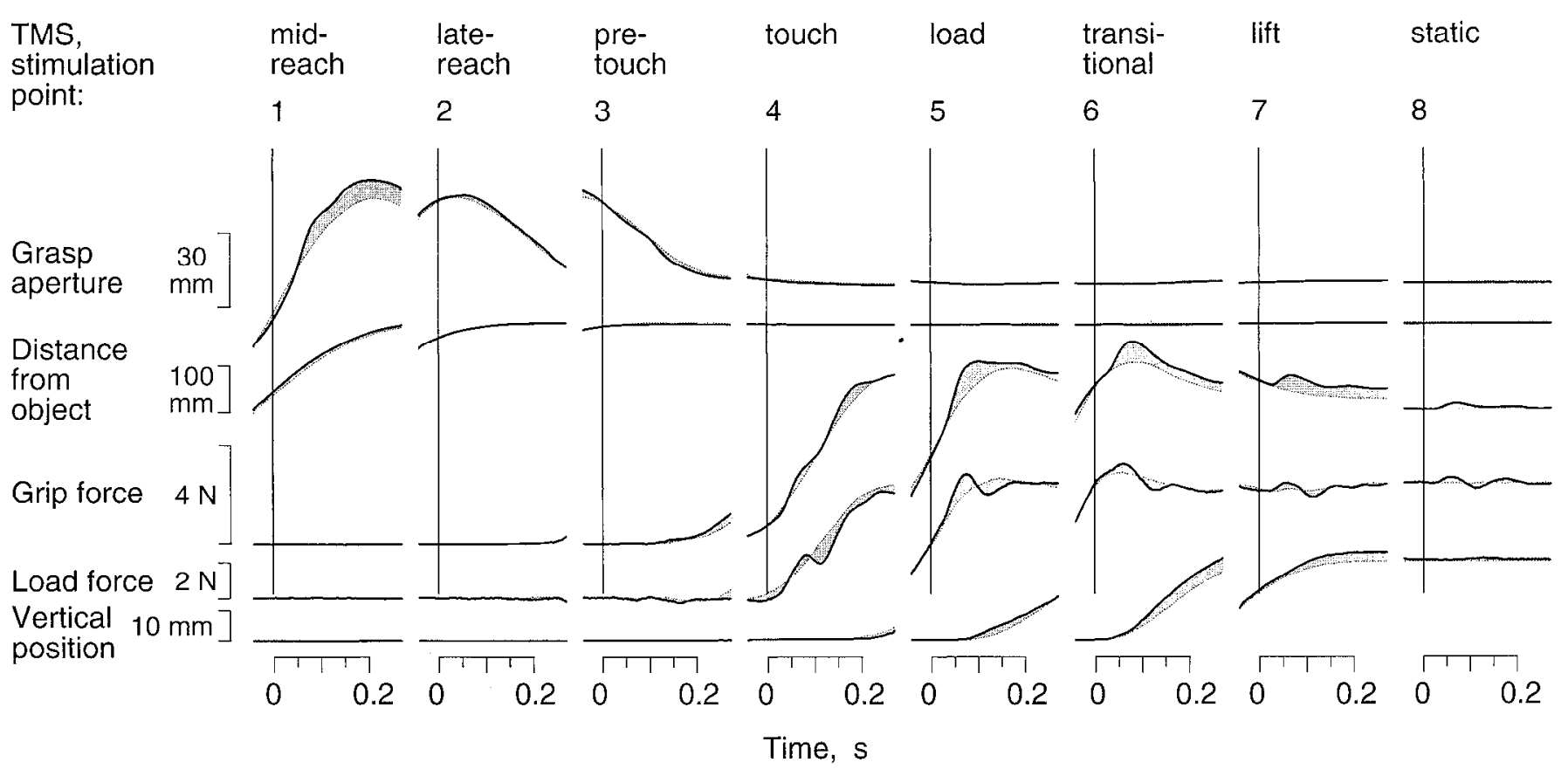

Figure 7. Ensemble averages across all subjects and all trials showing the effects of TMS on task performance. Data from trials with TMS (thick line) are compared to control trials (thin line); the difference is marked by the hatched zone. The vertical line indicate the time of occurrence of the TMS. For each point of stimulation the data averaging was referenced to the delivery of TMS. For further details see Figure 2 caption. 

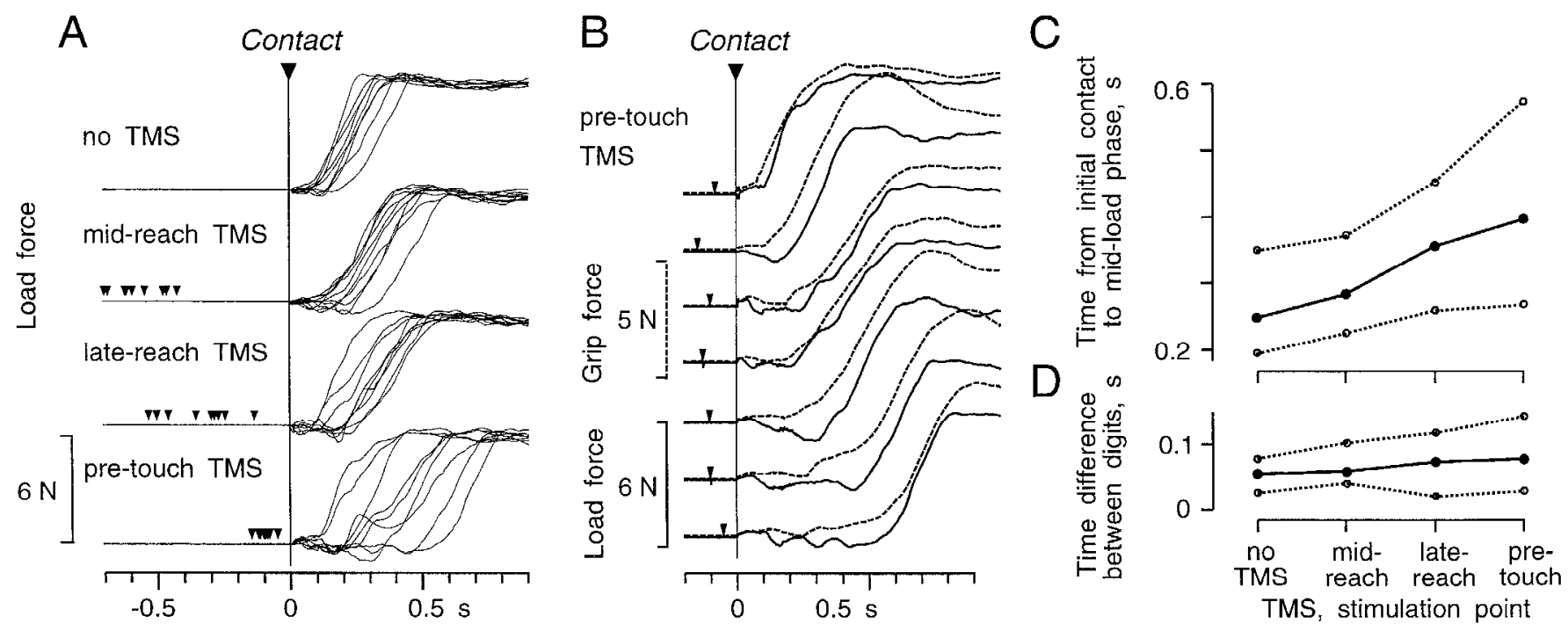

Figure 8. Delayed onset of the load phase following TMS delivered during reach. A, Load force development following initial contact wilh the object by a single subject during different stimulation conditions; no TMS, mid-reach TMS, late-reach TMS, and pre-touch TMS. All nine trials belonging to the test block for each condition are superimposed and synchronized to the moment at which the leading digit first contacted the object. The timing of the magnetic stimuli is indicated by arrowheads, and their variability in time is due to the fact that they were triggered on the basis of spatial coordinates (see Materials and Methods). $B$, The development of the grip and lift forces following TMS were delayed in parallel. The grip force (dashed curves) and load force (solid curves) are superimposed for each of seven single trials from the pretouch TMS condition shown in $A$. The calibration bars for grip force (dashed) and load force (solid) apply to all seven trials. $C$, delay from the leading digit contacting the object till the load force had reached $50 \%$ of the force necessary to lift-off the object, that is, $3.2 \mathrm{~N}$. This delay was significantly influenced by the TMS condition ( $P<0.00001$, Kruskal-Wallis). $D$, Time difference between leading and lagging digit making contact with the object was comparatively little influenced by the TMS. $C$ and $D$, Solid curve, lower, and upper dotted curves represent median, 25th, and 75th percentiles, respectively. Data from all subjects pooled.

fects were coserved in trials in which TMS was delivered during pre-touch (Fig. 8A). Interestingly, this increase in the duration of the preload phase was highly variable. For instance, in some trials with the pre-touch stimulation there was no apparent influence whereas in other trials the preload phase could last for more than $0.5 \mathrm{sec}$ (Fig. 8A,B). Also note that the extension of the preload phase was genuine because the development of both the grip and load forces were influenced in parallel (Fig. 8B). The later in the reach phase that TMS has delivered, the longer and more variable was the preload phase. This was also reflected in the interval between initial digit contact and the development of force to a level $50 \%$ of that required to lift the object (Fig. $8 C$ ).

Although the time interval between TMS and the initial contact with the object could also vary (the delivery of the TMS were referenced to spatial coordinates; see Materials and Methods), there was no correlation between this interval and the duration of the preload phase for TMS at the mid-reach, late-reach, and pre-touch points $(P>0.4$, in all three instances; Spearman rank correlation). Furthermore, the effects elicited by TMS could not be fully explained by a disturbed contact pattern because the time interval between the first digit contacting the object (which was the index finger in $64 \%$ of the trials) and the second digit was comparatively little influenced by TMS (Fig. $8 D$ ).

\section{Discussion}

This study has demonstrated striking changes in the amplitude of EMG responses to TMS delivered to the hand area of the motor cortex during different phases of a natural task requiring subjects to reach out, grasp, and lift a small object. Different muscles showed varied patterns of modulation across successive phases of the task. The changes observed were not simply a reflection of the variation in muscular activity that occurred during the task. For each muscle, there were clear dissociations between the changes in amplitude of the response to TMS and the variation in background EMG present during the different phases of the task.

\section{Likely mechanisms underlying the phasic modulation of the EMG responses to TMS}

In interpreting the results of the present experiment, it is important to stress that there are excitability changes at different spinal and supraspinal levels during the course of the task. These include those generated by somatosensory input from the moving arm and gripping digits. Our results show that the changes in the amplitude of responses to TMS did not simply reflect changes in motoneuronal excitability: the peak:background ratio was not constant but could vary by up to $320 \%$ for data pooled across all subjects, and considerably more in individual subjects (e.g., Fig. 4C). Another possibility is that the modulation results from phase-dependent changes in the gain of cortico-motoneuronal transmission during particular phases of the task (see Bennett and Lemon, 1994), or in the excitability of the spinal interneuronal network, as demonstrated in experimental models of locomotion, respiration, mastication, etc. (see, for example, Armstrong and Drew, 1985; Rossignol et al., 1988; Perreault et al., 1994). A contribution of nonmonosynaptic corticospinal influences, including those relayed through propriospinal-like mechanisms (Burke et al., 1994; Gracies et al., 1994) to the later components of the response to TMS cannot be ruled out. In the cat, propriospinal pathways have been specifically implicated in the control of reaching (Alstermark et al., 1981), and one could speculate that they might also be of importance during the reach phase of our task. However, the earliest and largest component 
of the response of distal hand muscles to TMS has been shown to be monosynaptic in nature (Edgley et al., 1990; Baldiserra and Cavallari, 1993). Therefore, changes in the excitability of segmental interneuronal or propriospinal pathways would be less likely to influence this component without a concomitant alteration in the level of target motoneuronal activity.

Having considered these different alternatives, it would appear that the most likely explanation of the dramatic changes in corticospinal influence over some of the muscles investigated during different phases of the task is that they reflect task-related variation in cortical excitability probed by low intensity TMS. Direct evidence for this has recently been obtained by recording the corticospinal volley evoked by TMS from the pyramid of a macaque monkey, and showing that its amplitude fluctuates with the level of cortical activity (Baker et al., 1994). A particularly large corticospinal volley would be generated if corticospinal cells were themselves active at the time of delivery of TMS, thereby increasing their susceptibility to discharge by magnetic stimulation (see Flament et al., 1993). In the monkey, 18/33 cortico-motoneuronal (CM) cells facilitating hand muscle activity were found to show a phasic-tonic pattern of discharge during performance of a precision grip (Maier et al., 1993). The phasic bursts of CM cells were greatest when monkeys positioned the tips of their digits upon the levers of a manipulandum (Muir and Lemon, 1983; Lemon et al., 1986). Phasic-tonic CM neurones have rapidly conducting axons, and these neurones tend to have the lowest threshold for excitation by TMS (Edgley et al., 1992). As might be predicted, we have recently been able to show that the amplitude of the corticospinal volley evoked by TMS va ies during different plases of the precision grip lask performed by the monkey (S. N. Baker, E. Olivier, and R. N. Lemon, unpublished observations).

The sensitivity of phase-related modulation of the peak:background ratio to the intensity of TMS is consistent with the idea that the amplitude of the EMG responses to TMS reflects, in part, the degree of cortical activity present when TMS is delivered. At the higher intensity, responses to TMS appeared to be roughly proportional to the background EMG, indicating that these strong stimuli activated corticospinal neurons irrespective of their excitatory state (see also Ohki et al., 1994). This was true for responses in all six muscles investigated.

We cannot exclude the presence of complex phase dependent nonlinear interactions between motor units already activated during the task and the influences of the corticospinal volley triggered by TMS. For the intrinsic hand muscles it has been shown that there can be very large increases in response amplitude with only small changes in voluntary background EMG (Hess et al., 1987; Kischka et al., 1993). Interestingly, and in agreement with our arguments concerning the contribution of cortical mechanisms, this behavior has been interpreted as evidence in favor of a cortical site of facilitation (Kischka et al., 1993, p 511). In any case such complex interactions could hardly explain those cases in which an inverse relationship was observed between changes in the background EMG and the amplitude of responses to TMS. It is noteworthy that these inverse relationships were also lacking when higher intensities of TMS were used.

Our observations add to a growing body of evidence that responses to TMS are influenced by the level of cortical excitability (Datta et al., 1989; Day et al., 1991; Deuschl et al., 1991; Flament et al., 1993; Johansson et al., 1994).
Modulation of responses to TMS during different phases of the task

Reach phases. During reach the overall goal is to transport the hand towards the object and to orientate and shape the hand and digits so that a stable grasp can be established (Jeannerod 1984, 1986). The mid- and late-reach TMS were delivered during these actions. When preshaped, positioned, and oriented the arm, palm, and digits are transported in a direction to make precise contact with the object. The pre-touch TMS was delivered during this phase. Contact with the object arrests hand and arm movements, and the grasp is activated. Both anterior deltoid and brachioradialis, which have an obvious role in transporting the hand, showed their maximum peak:background ratios during the reach, although the deltoid ratio was rather uniform throughout the task. Our results suggest that brachioradialis was subjected to a strong excitatory cortical drive during reaching. Many studies have shown that monkey M1 neurons whose activity is related to proximal muscles discharge during reaching (Lemon et al., 1976; Georgopoulos et al., 1982; Fu et al., 1993) and that they are recruited earlier than are neurones with more distal involvement (Murphy et al., 1985). Indeed, these proximal ncurons can be shown to modulate the activity of the distal units (Kwan et al., 1987).

Interestingly, the pattern of modulation we have observed in the more proximal muscles was also seen in the extrinsic finger muscles, EDC and FDS. After the grip had been established ('touch' in Fig. 2) the peak:background ratios of these muscles fell rapidly during the subsequent phases of object manipulation. Both FDS and EDC are involved both in the orientation of the palm and positioning of the finger tips, and both would appear to have been strongly influenced by the motor cortex throughout the reach, that is, until confirmation had been obtained that a secure grip had been established. This would be verified by contact responses in the tactile afferents supplying the finger tips (Westling and Johansson, 1987).

Initial manipulation phases. TMS delivered just after the subject first touched the object produced the largest relative responses in two of the muscles tested (1DI and AbPB). This observation is in line with our initial hypothesis that the influence of the motor cortex over the hand muscles should be particularly high during the early phases of the manipulation. Tactile inputs are known to be essential for appropriate coordination of this task (Johansson and Westling, 1984, 1987; Westling and Johansson, 1984, 1987) and is therefore possible that this strong effect partly results from a central interaction between these inputs and TMS. Indeed, we have recently provided evidence that such interactions may occur while subjects respond to small, unpredictably occurring, step load increases imposed on an object restrained between the thumb and index finger (Johansson et al., 1994). Accordingly, tactile inputs are known to exert excitatory effects on a large proportion (around $58 \%$ ) of monkey motor cortex neurons related to hand movement (Lemon, 1981; Picard and Smith, 1993). In the case of the AbPB, there was also an increase in the peak:background ratio during the pretouch phase. This may have been concerned with final adjustments of grip aperture prior to contact.

Hold phase. It is interesting to consider why the responses to TMS during the static, lift phase were smaller that at almost any other time during the task. It is possible that the cortical drive to the muscles during this phase is much reduced compared to the manipulation phase and that it derived mainly from tonically 
firing corticospinal neurons (Smith et al., 1975; Wannier et al., 1991 ) with slowly conducting axons (Evarts et al., 1983; Maier et al., 1993). Because these slow neurones are generally less susceptible to discharge by TMS (Edgley et al., 1992), there may be a smaller CM volley during the static phase, resulting in smaller EMG responses. An alternative explanation of the smaller responses during static grip is that the parameterization of the motor output to suit the physical properties of the object (friction, shape, and weight etc.) are carried out under cortical control during the early phases of manipulation. But once adequately parameterized, the cortical influence over the motor output would not be needed and the function of maintaining a stable grasp may thereafter be taken over by subcortical mechanisms.

\section{Disturbances in task performance produced by TMS}

The observation that TMS can produce delays in the execution of a voluntary task was first made by Day el al. (1989b). The generally weak stimuli used in this study did not impair subjects' ability to carry out the task. However, TMS delivered late during the reach did significantly delay the onset of loading phase characterized by an parallel increase in the grip and load forces. During the late-reach phase it could be that the cortical control is undergoing a critical transition from reach to grasp-related programs, and that this control is therefore particularly vulnerable to disruption by TMS at this time. The onset of the loading phase is usually triggered by tactile signals that serve as efficient indicators that the contact with the object has been established at each of the involved digits (Westling and Johansson, 1987). It is obviously inappropriate to apply any lifting forces until the afferent signals reliably signal a stable grip of the object; the onset of lift force may be delayed until such signals are available. Magnetic stimulation during reach and pre-touch may disturb this process by causing unexpected movennent of the digits, thereby causing a mismatch between the actual spatio-temporal pattern of afferent information and the expected pattern when the object is contacted. Interestingly, some subjects reported paresthesias when TMS was delivered at pre-touch or touch, but not at other times. TMS may also interfere with the use of tactile information by the cortex, and it should be possible to differentiate these central and peripheral mechanisms by more detailed studies of the timing of TMS relative to task performance.

In conclusion, this study shows that TMS can be used to probe normal control processes of natural prehension tasks (see also Johansson et al., 1994). We interpret our results as showing a significant and heterogenous variation in cortical activity during the evolution of the reach, grasp and lift task. Moreover, our data indicate that TMS can cause a characteristic disruption of neural processes critical for task control.

\section{References}

Alstermark B, Lundberg A, Norrsell U, Sybirska E (1981) Integration in descending motor pathways controlling the forelimb in the cat. 9. Differential behavioural defects after spinal cord lesions interrupting defined pathways from higher centres to motoneurones. Exp Brain Res 42:299-318.

Armstrong DM, Drew T (1985) Forelimb electromyographic responses to motor cortex stimulation during locomotion in the cat. J Physiol (Lond) 367:327-351

Baker SNB, Olivier E, Lemon RN (1994) Recording the pyramidal volley evoked by transcranial magnetic stimulation in a conscious monkey. Exp Brain Res 99:529-533.

Baldissera F, Cavallari P (1993) Short latency subliminal effects of transcranial magnetic stimulation on forearm motoneurones. Exp Brain Res 96:513-518.
Bennett KMB, I emon RN (1994) The influence of single monkey cortico-motoneuronal cells at different levels of activity in target muscles. J Physiol (Lond) 477:291-307.

Burke D, Gracies JM, Mazevet D, Meunier S, Pierrot Deseilligny E (1994) Non-monosynaptic transmission of the cortical command for voluntary movement in man. J Physiol (Lond) 480:191-202.

Colebatch JG, Deiber MP, Passingham RE, Friston KJ, Frackowiak RSJ (1991) Regional cerebral blood flow during voluntary arm and hand movements in human subjects. J Neurophysiol 65:1392-1401.

Datta AK, Harrison LM, Stephens JA (1989) Task-dependent changes in the size of the response to magnetic brain stimulation in human first dorsal interosseous muscle. J Physiol (Lond) 418:13-23.

Day BL, Dresslet D, Maertens De Noordhout A, Marsden CD, Nakashima K, Rothwell JC, Thompson PD (1989a) Electric and magnetic stimulation of human motor cortex: surface EMG and single motor unit responses. J Physiol (Lond) 412:449-473.

Day BL, Rothwell JC, Thompson PD, Maertens de Noordhout A, Nakashima K, Shannnon K, Marsden CD (1989b) Delay in the execution of voluntary movement by electrical or magnetic brain stimulation in intact man. Brain 112:649-663.

Day BL, Riescher H, Struppler A, Rothwell JC, Marsden CD (1991) Changes in the response to magnetic and electrical stimulation of the motor cortex following muscle stretch in man. J Physiol (Lond) 433: $41-57$.

Deuschl G, Michels R, Berardelli A, Schenck E, Inghilleri M, Lucking C.H (1991) Effects of electrical and magnetic transcortical stimulation on long latency reflexes. Exp Brain Res 83:403-410.

Edgley SA, Eyre JA, Lemon RN, Miller S (1990) Excitation of the corticospinal tract by electromagnetic and electrical stimulation of the scalp in the macaque monkey. J Physiol (Lond) 425:301-320.

Edgley SA, Eyre JA, Lemon RN, Miller S (1992) Direct and indirect activation of corticospinal neurones by electrical and magnetic stimulation in the anaesthetized macaque monkey. J Physiol (Lond) 446 : $224 \mathrm{P}$.

Espinoza E, Smith AM (1990) Purkinje cell simple spike activity during grasping and lifting objects of different textures and weights. J Neurophysiol 64:698-714

Evarts EV, Fromm C, Kröler J, Jennings VA (1983) Motor cortex control of finely graded forces. J Neurophysiol 49:1199-1215

Flament D, Goldsmith P, Buckley CJ, Lemon RN (1993) Task dependence of responses in first dorsal interosseous muscle to magnetic brain stimulation in man. J Physiol (Lond) 464:361-378.

Fu GG, Suarez I, Ebner TJ (1993) Neuronal specification of direction and distance during reaching movements in the superior precentral premotor area and primary motor cortex of monkeys. J Neurophysiol 70:2097-2117.

Georgopoulos AP, Camaniti R, Kalaska JF, Massey JT (1982) On the relations between the direction of two-dimentional arm movements and cell discharge in primate motor cortex. J Neurosci 2:1527-1537.

Goodale MA, Milner AD (1992) Separate visual pathways for perception and action. Trends Neurosci 15:20-25.

Gracies JM, Meunier S, Pierrot-Deseilligny E (1994) Evidence for corticospinal excitation of presumed propriospinal neurones in man. $J$ Physiol (Lond) 475:509-518.

Hess CW, Mills KR, Murray NMF (1987) Responses in small hand muscles from magnetic stimulation of the human brain. J Physiol (Lond) 388:397-419.

Iberall T, Bingham G, Arbib MA (1986) Opposition space as a structuring concept for the analysis of skilled hand movements. Exp Brain Res Suppl 15:158-173.

Jeannerod $M$ (1984) The timing of natural prehension movements. J Motor Behav 16:235-254.

Jeannerod M (1986) The formation of finger grip during prehension. A cortically mediated visuomotor pattern. Behav Brain Res 19:99116.

Johansson RS, Cole KJ (1994) Grasp stability during manipulative actions. Can J Physiol Pharmacol 72:511-524.

Johansson RS, Westling G (1984) Roles of glabrous skin receptors and sensorimotor memory in automatic control of precision grip when lifting rougher or more slippery objects. Exp Brain Res 56:550-564.

Johansson RS, Westling G (1987) Signals in tactile afferents from the fingers eliciting adaptive motor responses during precision grip. Exp Brain Res 66:141-154.

Johansson RS, Westling G (1988) Programmed and reflex actions to rapid load changes during precision grip. Exp Brain Res 71:59-71. 
Johansson RS, Lemon RN, Westling G (1993) Cortical influence over precision grip in man is strongly modulated during different phases of the task. J Physiol (Lond) 459:469P.

Johansson RS, Lemon RN, Westling G (1994) Time varying enhancement of human cortical excitability mediated by cutaneous inputs during precision grip. J Physiol (Lond) 481:761-775.

Kischka U, Fajfr R, Fellengerg T, Hess CW (1993) Facilitation of motor evoked potentials from magnetic brain stimulation in man: a comparative study of different muscles. J Clin Neurophysiol 10:503510 .

Kuypers HGJM (1981) Anatomy of the descending pathways. In: Handbook of physiology-the nervous syslem II (Brooklad JM, Mountcastle VB, eds), pp 597-666. Bethesda, MD: American Physiological Society.

Kwan HC, Murphy JT, Wong YC (1987) Interactions between neurons in precentral cortical zones controlling different joints. Brain Res 400: $259-269$.

Lemon RN (1981) Functional properties of monkey motor cortex neurones receiving afferent input from the hand and fingers. J Physiol (Lond) 311:497-519.

Lemon RN (1993) Cortical control of the primate hand. The $1992 \mathrm{G}$. L. Brown prize lecture. Exp Physiol 78:263-301.

Lemon RN, Hanby JA, Porter R (1976) Relationship between activity of precentral neurones during active and passive movements in conscious monkeys. Proc R Soc Lond [Biol] 194:341-373.

Lemon RN, Mantel GWH, Muir RB (1986) Corticospinal facilitation of hand muscles during voluntary movement in the conscious monkey. J Physiol (Lond) 381:497 527.

Maier M, Bennett KMB, Hepp-Reymond M-C, Lemon RN (1993) Contribution of the monkey cortico-motoneuronal system to the control of force in precision grip. $\mathbf{J}$ Neurophysiol 69:772-785.

Muir RB, Lemon RN (1983) Corticospinal neurons with a special role in precision grip. Brain Res 261:312-316.

Murphy JT, Kwan HC, Wong YC (1985) Sequential activation of neurons in primate motor cortex during unrestrained forelimb movements. J Neurophysiol 53:135-115.

Neter J, Wasserman W, Kutner MH (1989) Applied linear regression models, 2nd edition. Boston: Irwin.

Ohki Y, Suzuki T, Ugawa Y, Uesaka Y, Sakai K, Kanazawa I (1994)
Excitation of the motor cortex associated with the E2 phase of cutaneous reflexes in man. Brain Res 633:343-347.

Palmer E, Ashby P (1992a) Corticospinal projections to upper limb motoneurones in humans. J Physiol (Lond) 448:397-412.

Palmer E, Ashby P (1992b) Evidence that a long latency stretch reflex in humans is transcortical. J Physiol (Lond) 449:429-440.

Paulignan Y, MacKenzie C, Marteniuk R, Jeannerod M (1991) Selective perturbations of visual input during prehension movements. 1. The effects of changing object position. Exp Brain Res 83:502-512.

Pause M, Kunesch E, Binkofski F, Freund HJ (1989) Sensorimotor disturbances in patients with lesions of the parietal cortex. Brain 112: 1599-1625.

Perreault M-C, Rossignol S, Drew T (1994) Microstimulation of the medullary reticular formation during fictive locomotion. J Neurophysiol 71:229-245.

Picard N, Smith AM (1993) Primary motor cortical activity related to weight and texture of a grasped object. J Neurophysiol 68:18671881.

Porter R, Lemon RN (1993) Corticospinal neurones and voluntary movement, pp 428. Oxford: Oxford UP.

Rossignol S, Lund JP, Drew T (1988) The role of sensory inputs in regulating patterns of rhythmical movements in higher vertebrates. A comparison between locomotion, respiration and mastication. In: Neural control of rhythmic movements in vertebrates (Cohen A, Rossignol S, Grillner S, eds), pp 201-283. New York: Wiley.

Rothwell JC, Thompson PD, Day BL, Boyd S, Marsden CD (1991) Stimulation of the human motor cortex through the scalp. Exp Physiol 76:159-200

Siegel S, Castellan, NJ (1988) Nonparametric statistics for the behavioral sciences, second edition. New York: McGraw Hill.

Smith AM, Hepp-Reymond MC, Wyss UR (1975) Relation of activity in precentral cortical neurons to force and of force change during isometric contractions of finger muscles. Exp Brain Res 23:315-332.

Wannier TMJ, Maier MA, Hepp-Reymond M-C (1991) Contrasting properties of monkey somatosensory and motor cortex neurons activated during the control of force in precision grip. J Neurophysiol 65:572-589.

Westling G, Johansson RS (1984) Factors influencing the force control during precision grip. Exp Brain Res 53:277-284.

Westling G, Johansson RS (1987) Responses in glabrous skin mechanoreceptors during precision grip in humans. Exp Brain Res 66:128140 . 